Print ISSN: 2233-4165 / Online ISSN: 2233-5382

doi:http://dx.doi.org/10.13106/ijidb.2018.vol9.no4.69.

\title{
A Study on Supplier Involvement and Buyer Strategic Decisions
}

\section{공급자 참여와 전략적 선택에 대한 실증적 연구}

\author{
Sunil Hwang(황선일)*, Eung-Kyo $\operatorname{Suh}(\text { 서응교 })^{* *}$
}

Received: March 5, 2018. Revised: March 15, 2018. Accepted: April 15, 2018.

\section{Abstract}

Purpose - In the development of new products, suppliers involvement and developing products jointly can be said to be strategic activities that utilize the lack of knowledge from external organizations. In this new product development, supplier involvement has been proven to have a positive impact on new product development performance for a long time by previous research. However, sufficient academic research has not been conducted on the influence of supplier involvement in various product strategies or sales strategies that buyers make in order to secure a competitive advantage in the market. This study argues that product strategy and sales strategy used by buyers in the development of new products will control the effect of supplier involvement on new product development performance in order to compensate the lack of these academic aspects.

Research design, data, and methodology - Specifically, we selected the modularization strategy of the product as the product strategy, which is considered as an important strategy in the new product development through the preceding research, and the mass customer satisfaction strategy was chosen as the sales strategy. In order to achieve these research objectives, regression analysis was conducted using data from manufacturing productivity panel collected jointly by the Ministry of Industry, Trade and Industry and the Korea Productivity Center.

Results - As a result, supplier involvement and new product development performances (development cost efficiency, customer satisfaction) were positively related. The product modularity strategy proved to have an interactive effect on the relationship between supplier involvement and new product development performances (development cost efficiency, customer satisfaction). However, it has not been confirmed that there is a statistically significant interaction effect between supplier involvement and new product development performances.

Conclusions - Supplier involvement has positive relationships with NPD performance. In addition, product modularity strategies have interaction effects with supplier involvement and affect new product development performance (development cost efficiency and customer satisfaction). The results of this study are of academic significance in the case of lack of empirical studies on the effect of supplier participation on the effect of buyer 's strategy when a supplier participates and develops new products jointly.

Keywords: Supplier Involvement, Product Modulairty Strategy, Mass Customization Strategy.

JEL Classifications: D22, D24, O32.

\section{1. 서론}

점차 치열해지는 글로벌 경쟁과 급속한 기술의 발전은 시장 진입의 기회와 패턴을 변화시킴으로 인해서 기업들은 신제품

* First Author, Visiting Professor, Dept. of Operations, Decisions and Information, Yonsei School of Business, Seoul, Korea. E-mail: navyso@yonsei.ac.kr

** Corresponding Author, Professor, Graduate School of Business, Dankook University, Gyeonggi, Korea.

Tel: +82-31-8005-3981, E-mail: eungkyosuh@dankook.ac.kr
개발에 지속적으로 투자하는 것이 매우 중요해졌다. 심지어 신 제품 개발로서 단기간 이익을 내지 못하더라도 장기적으로 시 장에서의 생존을 위해서 뿐만 아니라, 궁극적으로 경쟁적 우위 를 확보하고 유지하기 위해서는 신제품의 개발이 더욱 중요해 졌다(Cooper \& Kleinschmidt, 1995; Schmidt, 1995; Fliess \& Becker, 2006; Yoon, 2016). 그러나 점점 빠르게 변화하는 기 업환경은 새로운 지식을 배워야 하는 필요성이 배움의 능력을 앞지르게 되었으며, 그로 인하여 단순한 지식소유의 비효율성 이 증가하게 되어 핵심지식을 제외한 나머지 지식은 외부로부 터 차용하게 되었다(Grant \& Baden-Fuller, 2004). 이와 같은 
현상은 신제품 개발에서 구매자가 해당 전문지식을 보유한 공 급자를 참여시켜 공동으로 제품을 개발하는 형태로 나타난다 (Grant \& Baden-Fuller, 2004).

과거 많은 논문들이 신제품 개발과 관련하여 공급자 참여에 대한 연구를 하였다. 초기의 논문들은 공급자의 참여가 신제품 개발에 어떠한 영향을 미치는지에 대한 연구가 대부분을 이루 었다(Clark, 1989; Clark \& Fujimoto, 1991). 그리고 공급자 참 여에 대한 선행요인에 대한 연구들이 그 뒤를 이었다(Primo \& Amundson, 2002; Koufteros, Vondermbse, \& Jayaram, 2005). 이러한 연구들은 다양한 이론적 틀에 따라 선행요인을 달리하 면서 공급자 참여에 어떠한 영향을 미치는지에 연구의 초점이 맞추어져 있었다(Koufteros, Cheng, \& Lai, 2007; Song \& Benedetto, 2008). 이와 함께 이러한 연합을 통하여 전략적 우 위를 획득하기 위한 구매자와 공급자간 관계에 대한 연구가 주를 이루었다(Chiesa \& Manzini, 1998; Gulati, 1998; Kamath \& Liker, 1994; Dyer \& Ouchi, 1993). 하지만 아쉽게도 구매자 의 전략과 공급자 참여를 동시에 고려한 연구는 많이 이루어 지지 않았다(Hsuan, 1999). 그러나 구매자과 공급자가 연합하 여 신제품을 개발하는 과정에서 구매자가 사용하는 전략에 따 라 공급자 참여가 신제품 개발 성과에 미치는 영향력이 달라 질 수 있다는 점은 매우 흥미로운 연구주제가 될 수 있다고 생각한다.

이와 같은 연구 목적을 위하여 본 연구는 제조업 분야에서 중요한 전략으로 선행연구에서 그 중요성이 입증된 제품 모듈 화 전략(Sanchez \& Mahoney, 1996; Baldwin \& Clark, 2000) 과 대량고객맞춤 전략(Davis, 1989; Kotha, 1995; 1996)을 선 택하였다. 그리고 구매자가 두 가지 전략을 사용했을 때에 공 급자 참여 효과는 어떻게 달라지는지 알아보는 것이 본 연구 의 목적이다.

본 논문의 구성은 다음과 같다. 먼저 연구의 이론적 배경 부분에서는 지식기반관점을 통한 공급자 참여, 제품 모듈화 전략, 그리고 대량고객만족 전략에 대한 선행연구의 고찰과 함께 기존연구의 한계점을 살펴보았다. 이어서 다음장에서 는 이를 바탕으로 한 연구모형과 구체적 가설을 제시하였 다. 아울러 가설을 검증하기 위해 사용한 자료 특징에 대해 서 설명하였다. 그리고 자료를 바탕으로 조절회귀분석을 하 여 가설을 통계적으로 검증하였다. 마지막으로 연구의 시사 점과 향후 연구방향에 대하여 논의하였다.

\section{2. 이론적 배경}

\section{1. 구매자 전략과 공급자 참여: 지식기반이론을 중심 으로}

Leuschner, Rogers, and Charvet(2013)에 의하면 지난 20 여년간 공급체인관리분야에서 공급자 참여 또는 소비자 참여 를 대상으로 연구한 논문은 무려 500 편이 해외에서 연구되었 다. 특히 공급자 참여가 제품 개발성과에 어떠한 영향을 미치 는지에 대한 실증적 연구도 80여편에 이르고 있다. 신제품 개 발에서 공급자 참여라는 것은 구매자와 공급자간 전략 및 프 로세스를 통합하는 과정으로 정의할 수 있다(Flynn, Huo, \& Zhao, 2010). 아울러 Petersen, Handfield, and Ragatz(2003) 은 구매자는 신제품 개발에 공급자를 참여시킴으로써 공급자 와 신제품 관련된 각종 정보들을 교환하며, 이를 통해 제품의
디자인의 수정부터 시작해서 제품 전략 기획, 생산 방법 등을 조정할 수 있다고 주장하였다. 이와 관련된 연구는 일본 자동 차회사와 미국 자동차 회사 간 제품 개발 프로젝트에 대한 연 구(Clark, 1989; Clark \& Fujimoto, 1991)를 시작으로 점차 범 위를 넓혀나가 전자산업(Eisenhardt \& Tabrizi, 1995)과 기계산 업(Hartley, Zirger, \& Kamath, 1997)으로 확장했다.

이와 같은 신제품 개발 시 공급자 참여 현상은 지식기반이 론(Knowledge Based View)으로 잘 설명되어진다. 지식기반이 론은 제한된 합리성으로 인하여 지식의 범위와 깊이를 동시에 가질 수 없는 개인과 형식지와 같은 지식은 거래가 가능하지 만, 암묵지와 같은 지식은 거래가 불가능한 시장의 한계를 극 복하는 조직의 형태가 기업이라고 주장한다(Kogut \& Zander, 1992). 기업은 내부 조직을 통하여 지시와 명령 그리고 루틴 (routine)으로 구성된 메커니즘으로 인하여 지식의 깊이와 범위 에 제한을 받지 않으며, 기업 내부에서 암묵지의 이전도 가능 하다(Kogut \& Zander, 1992). 하지만, 짧아지는 제품의 수명주 기와 광범위해지는 경쟁으로 인하여 하나의 기업에서 제품 제 작에 필요한 모든 지식을 소유하고 있는 것은 더 이상 효율적 이지 않게 되었다(Grant \& Baden-Fuller, 2004). 이에 따라 기 업들은 자신의 핵심역량이라고 생각하는 것 외에는 외부 기업 으로부터 제품 개발에 필요한 관련 지식을 빌려오게 되었는데 이것이 신제품 개발에서 공급자 참여의 형태로 나타나게 되었 다(Grant \& Baden-Fuller, 2004; Hwang \& Suh, 2017). 이와 같은 공급자 참여는 기업내부에서 모든 지식을 소유해야한다 는 부담감에서 벗어나게 해주었지만, 두 조직 간 지식을 어떻 게 효과적으로 통합할 것인지의 문제가 대두되었다. 특히 전문 지식을 보유한 기업은 자신들의 지식을 전달할 때에 상대방이 잘 이해할 것이라고 생각하지만, 실제적으로 그렇지 않다는 '지식의 저주(Curse of knowledge)' 현상이 발생할 수 있다 (Camerer, George, \& Martin, 1989). 특히 Kennedy(1995)에 의하면 특정분야의 전문가들은 자신들만의 전문지식과 자기들 만의 방식을 고집하는 경향으로 본인의 지식을 남들과 공유하 거나 설명할 때에 상대방은 이해하기 힘든 경우가 자주 발생 하는 것으로 나타났다. 이로 인하여 지식을 받은 입장에서는 자신들이 이해할 수 있는 정보가 부족하여 발생하는 불확실성 과 제공하는 정보나 지식을 이해하는데 다중적 의미로 해석할 수 있는 모호성이 발생하는 경우가 있다(Galbraith, 1973). 이 와 같은 현상을 해결하기 위하여 기업들은 많은 노력을 기울 이기 시작했고, 상호간 원활한 커뮤니케이션의 중요성이 높아 졌다(Kotabe, Martin, \& Domoto, 2003; Takeishi, 2001). 이러 한 가운데 구조적으로 불확실성과 모호성을 줄여줄 수 있는 제품 디자인 전략이 등장했는데 그것이 제품 모듈화 전략이다.

\section{2. 제품 모듈화 전략과 공급자 참여}

모듈화란 전체 시스템을 구성하고 있는 모듈이 내부적으로 는 상호 의존성을 지니지만, 모듈간에는 이와는 다르게 독립성 을 유지하고 있는 디자인을 말한다(Baldwin \& Clark, 2000). 모듈화된 디자인은 아키텍쳐와 인터페이스로 구분된다. 아키텍 쳐는 전체 시스템을 구성하는 모듈을 규정하는 것이며, 인터페 이스는 여러 모듈들이 상호간 연결과 소통 및 부합(fit)을 어떻 게 하는지를 의미한다(Bayliss \& Clark, 1997). 이러한 모듈화 의 특징은 표준화된 인터페이스를 만족시키면 이와 연결된 다 른 부분의 물리적 변화가 상호간 큰 영향을 미치지 않는다는 것이다. 
이와 같은 모듈화 디자인은 제품 생산방식에 큰 영향을 미 쳤다. 표준화된 인터페이스를 만족시키면 각 모듈제품을 동시 에 생산하는 것이 가능해졌기 때문이다. 그리고 모듈화 디자인 은 두 조직간 지식의 교환과 조합을 통해서 가치 있는 지식을 만들어내기 위한 공급자 참여에서 발생할 수 있는 여러 가지 문제를 해결해 주었다. 첫째, 모듈 간 표준화된 인터페이스만 명확하게 정의되고 그 기준에 부합하면 신제품을 공 개발하는 두 조직에서 지식교환 시 발생할 수 있는 불확실성과 모호성 을 줄여줄 수 있다(Grant \& Baden-Fuller, 2004). 불확실성은 정보의 부족을 의미하며 모호성은 해석의 다양성을 의미한다 (Galbraith, 1973). 정보나 지식을 이전했으나 수령자는 부족하 다고 느낄 수 있으며, 이전 받은 지식이나 정보를 발송자의 의 도와는 다르게 해석할 수 있다. 이러한 문제에 대해서 모듈화 는 표준화된 인터페이스라는 곳을 통하여 상호간의 접촉점을 최소화 시켜줌으로써 문제점이 발생할 수 있는 기회를 가능한 줄여준다. 둘째, 지식의 교환 시 발생할 수 있는 지식보호 성 향에 대해 효과적으로 대응할 수 있다(Grant \& Baden- Fuller, 2004). 신제품 공동개발 시 기업은 경쟁적 우위를 가지고 있 다고 판단하는 지식을 파트너에게로부터 보호하려는 성향이 있다. 첫째, 지식의 이전으로 소유권이 상실될 것으로 판단될 때, 둘째, 전달된 지식이 공급자를 통하여 나의 경쟁자에게도 유출될 가능성이 있을 경우, 셋째, 공급자에게 지식을 이전하 고 난 이후에도 지속적인 관리가 필요하다고 판단되는 경우가 이에 해당한다(Szulanski, 1996). 이러한 지식보호성향은 모듈 화된 디자인을 통해서 최소화시킬 수 있다. 핵심지식의 유출이 우려되는 경우 핵심지식을 보호할 수 있도록 공급자가 개발하 는 구성품과 느슨한 연결(loosely coupled)로 구성되는 디자인 을 적용하는 것이다. 이것은 구성품 간 인터페이스를 중심으로 두 조직간 연결을 느슨하게 하여 지식유출에 대한 위험을 줄 여주는 효과가 있다(Sanchez \& Mahoney, 1996).

\section{3. 대량고객맞춤 전략과 공급자 참여}

1987년부터 사용되기 시작한 대량고객맞춤은 기존의 대량 생산방식에서 벗어나 새로운 생산방식의 시작을 알리고 있었 다. 1980 년대부터 고객들의 제품에 대한 욕구가 높아지면서 기존의 소품종 대량생산의 방식으로는 다양한 소비자의 욕구 를 충족할 수 없게 되었기 때문이다. 이에 유연한 생산방식을 바탕으로 생산비용을 크게 늘리지 않으면서도 여러 소비자의 욕구를 충족시킬 수 있는 대량고객맞춤이란 개념이 등장하게 되었다. 학계에서는 기존의 대량생산체제에서 소요되는 비슷한 생산비용으로써 다양한 고객들의 요구를 만족시킬 수 있는 시 스템으로 대량고객맞춤을 정의한다(Hart, 1995; Davis, 1989).

이러한 대량고객맞춤은 다양한 고객의 요구사항이 제품에 반영되어야 하면서도 일대일 개인맞춤으로 하는 생산방식처럼 생산가격이 높아서는 안된다는 제한사항이 존재한다(Hart, 1995). 두 가지 요구사항은 기존 개념에서는 서로 상충되는 개념이다. 품목의 단가를 낮추기 위해서는 대량 생산을 통해 규모의 경제를 확보해야하는데, 이렇게 되면 다양한 고객들의 요구사항이 제품에 반영되기 어렵기 때문이다(Kay, 1993). 이 러한 문제를 해결하기 위해서는 기존의 대량생산방식으로는 해결할 수 없다. 결국 대량고객맞춤은 고객의 특별한 요구사항 을 제품에 반영해야 하는데, 그것을 반영할 수 있는 것은 기존 의 대량생산방식에서 사용하던 기계나 자동화를 통해서는 어 렵다. 소품종 소량생산으로 특별한 고객에서 맞춤 제작을 했던
기능인의 암묵지가 제품에 반영되어야 하기 때문이다(Kotha, 1996). 이것은 일본의 자전거 회사인 National Bicycle Industrial Company(NBIC) 사례에서도 잘 드러나 있듯이 기존의 대량생 산체계에서 대량고객맞춤용 자전거를 생산하기 위해서는 조직 내부 뿐만 아니라 조직간 원활한 지식의 교환과 가치 있는 지 식의 생산이 필수적이다(Kotha, 1995; 1996). 이러한 지식이 결국 조직의 경쟁적 우위를 가져오게 할 수 있는 자원이 된다.

\section{3. 가설 도출 및 연구모형}

\section{1. 공급자 참여와 신제품 개발 성과}

구매자는 능력있는 공급자를 신제품 개발과정에 참여시킴으 로써 신제품 개발 성과를 향상시킬 것으로 기대할 수 있다. 공 급자가 보유하고 있는 지식을 신제품 개발에서 발생하는 문제 를 해결하는데 사용할 수 있기 때문이다(Carr, Kaynak, \& Hartley, 2008). 구체적으로 공급자와 함께 시장에서 경쟁전략 을 조율하고, 제품의 생산계획 등을 함께 조정함으로 공급체인 관리의 전반적인 효율성을 증대시킬 수 있다(Holcomb \& Hitt, 2007). 그리고 구매자는 본인이 소유하지 않은 전문 지식과 기술 등을 활용할 수 있는데 이것은 궁극적으로 신제품 개발 성과에 긍정적 영향을 미치는 것으로 알려져 있다(Petersen et al., 2003).

이에 대한 선행연구로서 Ragatz, Handfield, and Scannell (1997)은 공급자 참여가 제품의 품질, 비용 및 리드타임에 긍 정적 영향을 미친 다는 것을 60 개의 제조 기업을 대상으로 한 실증연구에서 증명하였다. 그리고 McGinnis and Vallopra (1999)는 공급자 참여가 품질과 더불어서 제품 출시시기를 앞 당겨 고객의 만족도를 증대한다고 주장하였다. 그리고 Kessler, Bierly, and Gopalakrishnan(2000)은 신제품 개발의 전반적인 비용을 절약하는데 공급자의 참여가 긍정적인 역할을 한다고 주장하였다. 따라서 아래와 같은 가설을 세울 수 있다.

<가설 1-1> 신제품 공동개발에서 공급자의 참여는 신제품 개발 성과(개발비용의 효율성)와 긍정적 관계가 있을 것이다.

<가설 1-2> 신제품 공동개발에서 공급자의 참여는 신제품 개발 성과(고객만족)와 긍정적 관계가 있을 것 이다.

\section{2. 공급자 참여와 제품 모듈화 전략의 상호작용 효과}

모듈화의 특징은 인터페이스로 연결된 구성품의 물리적 변 화가 다른 구성품에 큰 영향을 주지 않는다는 것이다(Baldwin \& Clark, 2000). 이러한 특징은 신제품 개발 시 공급자가 참여 하여 공동으로 제품을 개발할 때 상호작용 효과를 나타낼 것 으로 판단된다. 예를 들어 구매자와 공급자간 신제품을 공동으 로 개발할 때에 단순히 공급자를 참여시키는 것보다는 공급자 참여시 모듈화 전략을 적용한다면, 공급자가 표준화된 인터페 이스의 조건을 만족할 경우 두 조직이 동시에 각 구성품의 개 발을 할 수 있기 때문이다. 이것은 전반적인 신제품의 개발시 간을 단축시킬 수 있어 효율성을 높일 수 있다. 그리고 줄어든 시간만큼 신제품 개발 프로젝트 비용을 절감할 수 있고 이는 
제품의 제작단가에 반영되어 고객 만족을 증대시킬 것으로 판 단된다.

<가설 2-1> 제품의 모듈화 전략은 신제품 공동개발에서 공 급자의 참여와 신제품개발 성과(개발비용의 효 율성)간 관계에서 조절변수 역할을 할 것이다.

<가설 2-2> 제품의 모듈화 전략은 신제품 공동개발에서 공 급자의 참여와 신제품개발 성과(고객만족)간 관 계에서 조절변수 역할을 할 것이다.

\section{3. 공급자 참여와 대량고객맞춤 전략의 상호작용 효과}

대량고객맞춤 전략의 핵심은 대량생산비용으로 다양한 고객 의 욕구를 충족시켜줄 수 있는 것이다. 이것은 일본 자전거 회 사 NBIC의 사례에서도 보았지만, 기존의 대량생산 시스템으로 는 해결할 수 없다. 새로운 지식의 창조를 위해 다양한 지식의 교환과 조합이 필요하다. 특히 다양한 고객의 특별한 요구를 제품에 반영시키기 위해서는 장인의 노하우가 담긴 지식이 필 요하다. 하지만, 짧아지는 제품의 수명주기를 고려 할 때에 모 든 지식을 하나의 조직에서 소유하고 있기는 비효율적이다. 따 라서 이러한 지식이 필요한 경우 외부 조직으로부터 지식을 빌려오는 것이 경제적일 것으로 판단한다(Kogut \& Zander, 1992; Cho, 2016).

이와 같은 현상을 종합적으로 판단했을 때 단순히 공급자 참여를 통한 신제품 개발보다는 공급자 참여시 대량고객맞춤 전략을 적용하여 신제품 개발을 한다면, 효율적으로 활용할 수 있는 외부의 전문지식을 제품에 적용할 수 있으므로 신제품 개발 성과인 제작단가에는 상호작용 영향을 미칠 것으로 예상 한다. 아울러 자체적인 전문지식을 습득하여 제품을 개발하는 것 보다는 외부 조직의 특화된 지식을 차용하여 제품에 반영 함으로써 고객만족도 증가시킬 수 있다고 판단할 수 있다. 따 라서 아래와 같은 가설을 세울 수 있다.
<가설 3-1> 대량고객맞춤 전략은 신제품 공동개발에서 공 급자의 참여와 신제품개발 성과(개발비용의 효 율성)간 관계에서 조절변수 역할을 할 것이다.

<가설 3-2> 대량고객맞춤 전략은 신제품 공동개발에서 공 급자의 참여와 신제품개발 성과(고객만족)간 관 계에서 조절변수 역할을 할 것이다.

앞서 언급한 가설들을 바탕으로 <Figure 1>과 같이 연구모 형을 제시한다.

\section{4. 연구방법}

\section{1. 표본 추출 및 자료 수집}

본 연구에서 제시한 가설을 검증하기 위해 산업통상자원부 와 한국생산성본부가 공동으로 자료를 수집한 제조업 생산성 패널 데이터를 활용하였다. 자료의 특징은 자료 수집을 전문적 으로 실시하는 훈련된 조사원에 의하여 자료가 수집되었다는 것과 응답의 정확성을 높이기 위하여 재무, 인사, 기획관리, 영업기획, 생산관리, 구매관리 및 연구개발 등 모두 7 개 분야 로 나누어 정보를 수집했다는 점을 들 수 있다. 본 연구에서는 모두 601 개의 응답된 자료를 활용하였다.

자료 중 가장 많은 산업군은 일반기계 분야로서 모두 205 개의 기업이 응답하였다. 그리고 자동차 산업은 165 개, 통신산 업은 118 개, 조선산업은 113 개의 기업이 응답하였다, 응답기 업 중 대기업은 42 개 기업이 응답하였으며, 중소기업은 504개 기업이 응답하였다. 이 중 한국증권거래소에 상장한 기업은 18 개 이며, 코스닥에 상장한 기업은 54 개 기업이 응답하였다. 이와 같은 표본의 특성은 <Table $1>$ 에 정리하였다.

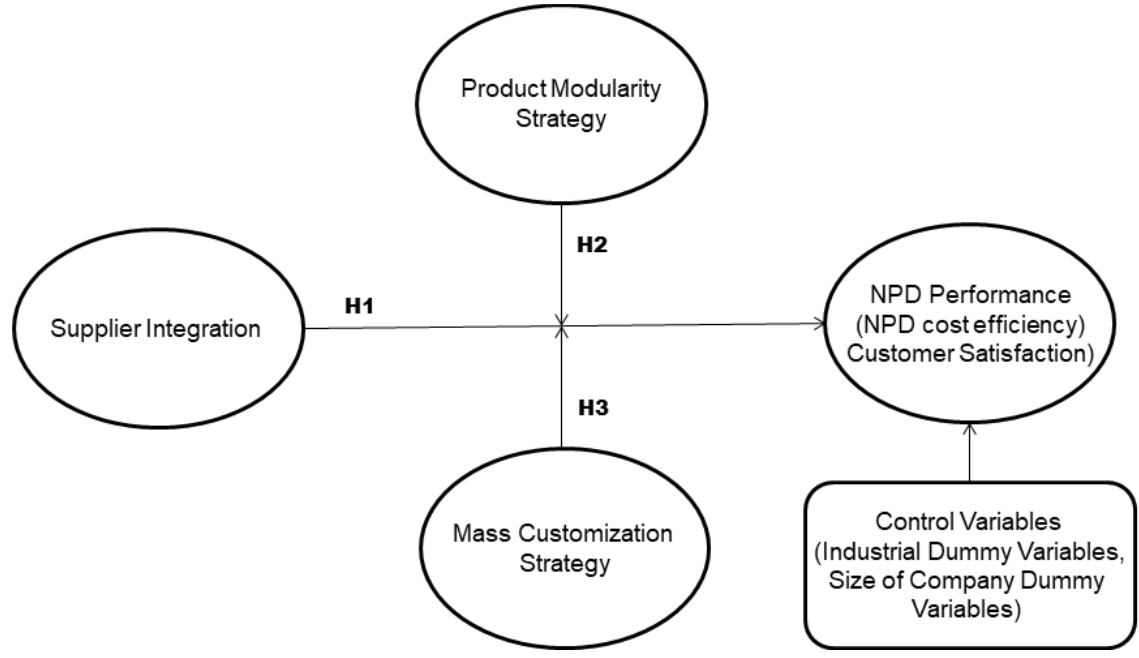

<Figure 1> Research Model 
<Table 1> Sample demographics

\begin{tabular}{|c|c|c|c|}
\hline \multicolumn{2}{|c|}{ Remarks } & Frequency & Ratio(\%) \\
\hline \multirow{5}{*}{ Industry } & $\begin{array}{c}\text { General } \\
\text { Machinery }\end{array}$ & 205 & 34 \\
\hline & Auto & 165 & 27 \\
\hline & Shipbuilding & 113 & 19 \\
\hline & Communication & 118 & 20 \\
\hline & Sub total & 601 & 100 \\
\hline \multirow{5}{*}{$\begin{array}{l}\text { Size of } \\
\text { Company }\end{array}$} & Large & 42 & 7 \\
\hline & Mid-size & 50 & 8 \\
\hline & $\begin{array}{c}\text { Mid-size } \\
\text { (suspension) }\end{array}$ & 5 & 1 \\
\hline & Small & 504 & 84 \\
\hline & Sub total & 601 & 100 \\
\hline \multirow{5}{*}{$\begin{array}{l}\text { Listing } \\
\text { Status }\end{array}$} & $\begin{array}{l}\text { Korean Stock } \\
\text { Exchange }\end{array}$ & 18 & 3 \\
\hline & KOSDAQ & 54 & 9 \\
\hline & $\begin{array}{c}\text { Unlisted } \\
\text { (External } \\
\text { Audit) }\end{array}$ & 163 & 27 \\
\hline & Unlisted & 366 & 61 \\
\hline & Sub total & 601 & 100 \\
\hline
\end{tabular}

\section{2. 측정 변수 및 통제변수}

본 연구를 위하여 사용된 설문 문항은 <Table 2>과 같다. 측정도구의 신뢰도를 높이기 위해 기존에 사용되었던 설문문 항을 차용하였으며, 불가피한 경우 연구목적에 맞게 수정한 것 을 확인하였다. 독립변수로서 사용한 공급자 참여는 Chen and Paulraj(2004)에서 공급자 참여(Supplier Involvement)를 측정하 기 위한 설문항목을 보완하여 적용하였다. 대량고객맞춤 전략 은 Tu, Vonderembse, and Ragu-Nathan (2001)에서 대량고객 맞춤(Mass customization)을 측정하기 위해 사용했던 설문 문 항 중 제품의 대량고객맞춤 전략능력, 제품의 다양성과 품질 등을 적용한 4 개 문항을 차용하였다. 제품의 모듈화 전략은 Forza and Salvador(2002) 및 Tu, Vonderembse, RaguNathan, and Ragu-Nathan(2004)에서 제품 모듈화(Product Modularity)를 측정하기 위해 사용했던 문항 중 디자인의 모듈 화 정도 및 공통 모듈화 정도 등을 측정한 2개를 수정 적용하 였다. 종속변수는 신제품 개발관련 선행연구에서 많이 사용되 었던 성과지표를 사용하였다(Vickery, Jayaram, Droge, \& Calantone, 2003; Shin, Collier, \& Wilson, 2000).

아울러 독립변수 및 조절변수가 종속변수에 미치는 효과를 효과적으로 측정하기 위하여 통제변수를 사용하였다. 자동차, 일반기계, 조선 및 통신 산업에서 발생할 수 있는 산업별 특징 이 종속변수에 미치는 영향을 통제하기 위하여 통신산업을 기 준으로 산업별 더미변수로 만들어 적용하였다. 그리고 기업의 규모에 따라 신제품 개발성과가 달라질 수 있다고 판단하여 중소기업을 기준으로 한 기업별 더비변수를 통제변수로 추가 하였다.
<Table 2> Measurement Variables

\begin{tabular}{|c|c|c|}
\hline Construct & No. & $\begin{array}{c}\text { Questions } \\
\text { (1=Not at all, } 4=\text { Somewhat, } \\
\text { 7=Very Well) }\end{array}$ \\
\hline \multirow{4}{*}{$\begin{array}{l}\text { Supplier } \\
\text { involvement }\end{array}$} & SI1 & $\begin{array}{l}\text { The two companies are involved in the } \\
\text { development process of new products. }\end{array}$ \\
\hline & $\mathrm{SI} 2$ & $\begin{array}{l}\text { Have suppliers actively propose new } \\
\text { technologies (or standards). }\end{array}$ \\
\hline & $\mathrm{SI} 3$ & $\begin{array}{l}\text { Suppliers are encouraged to participate in } \\
\text { solving problems that arise during the } \\
\text { development of new products for our } \\
\text { company. }\end{array}$ \\
\hline & $\mathrm{S} 14$ & $\begin{array}{l}\text { The two companies undertake a variety } \\
\text { of technical collaborations } \\
\text { (eg joint projects in new technology } \\
\text { development). }\end{array}$ \\
\hline \multirow{4}{*}{$\begin{array}{l}\text { Mass } \\
\text { Customizati } \\
\text { on } \\
\text { Strategy }\end{array}$} & MC1 & Various products can be produced. \\
\hline & MC2 & $\begin{array}{l}\text { The response to customer's order change } \\
\text { is smooth. }\end{array}$ \\
\hline & MC3 & $\begin{array}{l}\text { The response to rapid changes in output } \\
\text { is smooth. }\end{array}$ \\
\hline & MC4 & The response to model changes is smooth. \\
\hline \multirow[b]{2}{*}{$\begin{array}{l}\text { Product } \\
\text { Modularity } \\
\text { Strategy }\end{array}$} & PM1 & DFM(Design for Manufacturing) is applied. \\
\hline & PM2 & $\begin{array}{l}\text { DFV(product diversity-conscious design, } \\
\text { platform, common use, modularization, } \\
\text { etc.) is applied. }\end{array}$ \\
\hline \multirow{4}{*}{$\begin{array}{l}\text { Customer } \\
\text { Satisfaction }\end{array}$} & CS1 & $\begin{array}{l}\text { The customer is satisfied with the products } \\
\text { we offer. }\end{array}$ \\
\hline & CS2 & $\begin{array}{l}\text { The customer is satisfied with the various } \\
\text { services provided by our company. }\end{array}$ \\
\hline & CS3 & $\begin{array}{l}\text { Customers are satisfied with our response } \\
\text { to the problems they have raised. }\end{array}$ \\
\hline & CS4 & $\begin{array}{l}\text { The customer wants to maintain } \\
\text { long-term relationship with our company. }\end{array}$ \\
\hline $\begin{array}{l}\text { NPD c } \\
\text { efficien }\end{array}$ & \multicolumn{2}{|r|}{$\begin{array}{l}\text { Please compare with the industry average } \\
\text { (1=Very Low. } 4=\text { Same Level. } 7=\text { Very High) }\end{array}$} \\
\hline
\end{tabular}

\section{5. 실증분석}

\section{1. 측정도구의 단일차원성, 신뢰성 및 타당성}

측정도구의 단일차원성을 검증하기 위한 방법으로 탐색적 요인분석을 실시하였다. 모든 변수들이 앞서 예상한 하나의 구 성요인으로 높은 값을 보이며 적재되었다. 이로써 단일차원성 을 확보하였다고 할 수 있다(Koufteros et al., 2007). 그리고 <Table 4>에서와 같이 신뢰성을 확보하기 위하여 크론바흐 알 파 값을 사용하였는데 권고수준 0.7 을 상회하고 있어 모두 만 족하는 것을 알 수 있다. 따라서 측정도구의 신뢰도는 확보하 였다고 할 수 있다(Hair, Black, Babin, Anderson, \& Tatham, 2010).

다음으로 측정변수의 타당도를 검증하기 위해 $\mathrm{R}$ 프로그램 의 Lavaan 패키지를 이용하여 확인적 요인분석을 실시하였다. <Table 3>에서도 나와 있듯이 각 요인들은 모두 요인 적재량 0.7 이상을 상회하는 것을 알 수 있다. 그리고 이 모든 값은 
통계적으로 모두 유의한 값을 가지기 때문에 수렴 타당성이 확보되었다고 할 수 있다(Hair et al., 2010). 아울러 측정모형 의 주요 적합도는 $\mathrm{CFI}=0.991, \mathrm{TLI}=0.998$ 을 나타내고 있으며 표준화 RMSEA 값은 0.043 으로서 우수한 적합성을 나타내고 있다.

<Table 3> Convergent Validity, Reliability, and Statistical Values

\begin{tabular}{|c|c|c|c|c|c|}
\hline Constructs & No. & $\begin{array}{l}\text { Loading } \\
\text { value }\end{array}$ & Mean & S.D. & $\begin{array}{c}\text { Cronbach's } \\
\text { Alpha }\end{array}$ \\
\hline \multirow{4}{*}{$\begin{array}{l}\text { Supplier } \\
\text { Involvement } \\
\text { (SI) }\end{array}$} & SI1 & 0.789 & 4.58 & 1.374 & \multirow{4}{*}{.907} \\
\hline & $\mathrm{SI} 2$ & 0.878 & 4.58 & 1.315 & \\
\hline & $\mathrm{SI} 3$ & 0.888 & 4.60 & 1.333 & \\
\hline & $\mathrm{SI} 4$ & 0.818 & 4.35 & 1.294 & \\
\hline \multirow{2}{*}{$\begin{array}{c}\text { Product } \\
\text { Modularity } \\
\text { Strategy } \\
(\mathrm{PM})\end{array}$} & MD1 & 0.967 & 4.55 & 1.325 & \multirow{2}{*}{.913} \\
\hline & MD2 & 0.861 & 4.50 & 1.314 & \\
\hline \multirow{4}{*}{$\begin{array}{c}\text { Mass } \\
\text { Customizatio } \\
\text { n Strategy } \\
(\mathrm{MC})\end{array}$} & MC1 & 0.763 & 4.91 & 1.232 & \multirow{4}{*}{.913} \\
\hline & MC2 & 0.870 & 5.19 & 1.152 & \\
\hline & MC3 & 0.864 & 4.96 & 1.161 & \\
\hline & MC4 & 0.893 & 4.93 & 1.168 & \\
\hline
\end{tabular}

* All significant statistically at $p<0.001$

판별타당성은 Fornell and Larker(1981)가 제안한 평균분산 추출지수(AVE: Average Variance Extracted)와 구성요인들 간 의 상관계수의 제곱값을 비교하여 확인하였다. <Table $4>$ 에서 나와 있듯이 요인 간 상관계수의 제곱은 평균분산추출지수 보 다 작은 것을 확인할 수 있다. 따라서 판별타당성을 확보 하였 다고 할 수 있다.

$<$ Table 4> Correlation Coefficient and Average Variance Extracted

\begin{tabular}{|c|c|c|c|c|c|}
\hline Constructs & SI & PM & MC & AVE & SQRT AVE \\
\hline SI & 1 & & & 0.713 & 0.844 \\
\hline PM & $0.227^{* * *}$ & 1 & & 0.839 & 0.916 \\
\hline MC & $0.172^{* * *}$ & $0.296^{* * *}$ & 1 & 0.721 & 0.849 \\
\hline$* * *$ & $p<.01$
\end{tabular}

다음으로 동일방법편의 여부를 확인하기 위하여 보편적으로 활용되고 있는 Harman의 one-factor test를 활용하였다. 분석 결과 모든 측정변수들이 하나의 요인으로 수렴하지 않았으며, 총 설명된 분산은 $81.3 \%$ 이었다. 그리고 가장 높은 설명력을 가지는 요인이 $31.6 \%$ 의 분산을 설명하고 있으므로 동일방법 편의는 본 연구에서 크게 영향을 미치지 않는다는 것을 확인 하였다(Podsakoff, MacKenzie, Lee, \& Podsakoff, 2003).

\section{2. 가설의 검증}

본 연구의 목적은 구매자의 전략에 따라 공급자 참여가 신 제품 개발 성과 - 구매자 만족, 개발 비용 효율성 - 에 미치는 영향을 알아보는 것이다. 이를 위하여 기존의 연구들과 지식기
반이론을 바탕으로 6 개의 가설을 수립하였다. 가설을 검증하 기 위하여 SPSS 23.0 통계프로그램을 사용하였다. 특히 본 연구에서는 구매자의 전략과 공급자 참여의 상호작용에 대한 정확한 검증을 위해 Aiken and West(1991)의 권고를 따랐다. 즉 구매자의 전략 중 제품 모듈화 전략과 대량고객맞춤 전략 그리고 공급자 참여에 대하여 평균 중심화(mean centering)를 실시하고 상호작용 변수항을 만들어서 회귀식에 적용하였다. 분석결과는 <Table 5>에 잘 나타나있다. 조절회귀분석은 두 가지 종속변수(개발 비용 효율성, 고객만족)에 따라 각각 두 개의 모형을 표시하였다. 모형 1,3 은 통제변수인 산업더미 변 수와 기업별 더비변수 그리고 독립변수가 포함된 모형이다. 모 형 2, 4는 모형 1,3 에 상호작용항이 포함된 모형이다.

$<$ Table 5> Results of regression

\begin{tabular}{|c|c|c|c|c|c|}
\hline & \multicolumn{2}{|c|}{$\begin{array}{l}\text { D.V. : NPD cost } \\
\text { Efficiency }\end{array}$} & \multicolumn{2}{|c|}{$\begin{array}{l}\text { D.V. : Customer } \\
\text { Satisfaction }\end{array}$} \\
\hline & & Model 1 & Model 2 & Model 3 & Model 4 \\
\hline \multirow{3}{*}{$\begin{array}{l}\text { Industrial } \\
\text { Dummy }\end{array}$} & Auto & .169 & .167 & .081 & .085 \\
\hline & $\begin{array}{c}\text { General } \\
\text { Machinery }\end{array}$ & .079 & .071 & .014 & .026 \\
\hline & Shipbuilding & -.068 & -.073 & .090 & .102 \\
\hline \multirow{3}{*}{$\begin{array}{l}\text { Size of } \\
\text { firm } \\
\text { Dummy }\end{array}$} & Large & -.041 & -.045 & -.084 & -.077 \\
\hline & Mid & .127 & .139 & -.019 & -.023 \\
\hline & Mid(suspend) & .685 & .650 & .028 & .062 \\
\hline I.V. & $\begin{array}{c}\text { Supplier } \\
\text { Involvement } \\
\text { (SI) }\end{array}$ & $.198^{\star \star \star}$ & -.012 & $.136^{\star \star \star}$ & $.106^{\star \star \star}$ \\
\hline \multirow{4}{*}{ Moderator } & \begin{tabular}{|c|} 
Product \\
Modularity \\
Strategy (PM)
\end{tabular} & & $.59^{\star \star \star}$ & & $.089^{\star * \star}$ \\
\hline & $\begin{array}{c}\text { Mass } \\
\text { Customization } \\
\text { Strategy (MC) }\end{array}$ & & .066 & & $.184^{\star \star \star}$ \\
\hline & SI X PM & & $.040^{* *}$ & & $.043^{\star *}$ \\
\hline & $\mathrm{SI} \times \mathrm{MC}$ & & -.008 & & -.009 \\
\hline \multicolumn{2}{|r|}{$\mathrm{R}^{2}$} & .414 & .418 & .116 & .126 \\
\hline \multicolumn{2}{|c|}{ Adjusted $\mathrm{R}^{2}$} & .404 & .407 & .102 & .109 \\
\hline \multicolumn{2}{|r|}{$\mathrm{F}$} & 44.598 & 37.021 & 8.330 & 7.434 \\
\hline \multicolumn{2}{|c|}{$p$-value } & $<0.001$ & $<0.001$ & $<0.001$ & $<0.001$ \\
\hline
\end{tabular}

본 연구에서 이론적 배경 및 선행연구를 기반으로 세웠던 가설은 조절회귀분석 결과에 나타난 독립변수와 상호작용항의 통계적 유의성으로 검증을 하였다. 먼저 공급자 참여와 신제품 개발 성과간의 관계는 통계적으로 유의한 결과가 나왔다. 세부 적으로는 개발 비용 효율성(beta=.198, $\mathrm{p}=.001)$, 고객만족 (beta=.136, p=.001), 모두 신뢰수준 $99 \%$ 에서 유의한 통계값을 나타내었다. 이것으로 공급자 참여와 신제품 개발성과는 긍정 적 관계가 있을 것이라는 <가설 1>을 모두 채택하였다.

다음으로 공급자 참여와 제품의 모듈화 전략의 상호작용 효 과를 검증하였다. 공급자 참여와 제품의 모듈화 전략이 신제품 개발 성과 중 개발비용 효율성에는 상호작용 효과를 하는 것 으로 나타났다(beta=.040, p=.05). 그리고 고객만족에도 긍정적 
상호작용을 하는 것으로 확인되었다(beta=.043, p=.013). 이와 같은 상호작용 효과를 구체적으로 알아보기 위해 그림으로 나 타내었다(Aiken \& West, 1991). <Figure 2>는 제품의 모듈화 전략의 수준에 따라서 공급자 참여가 신제품 개발성과인 개발 비용 효율성에 어떻게 변화하는지를 나타내고 있다.

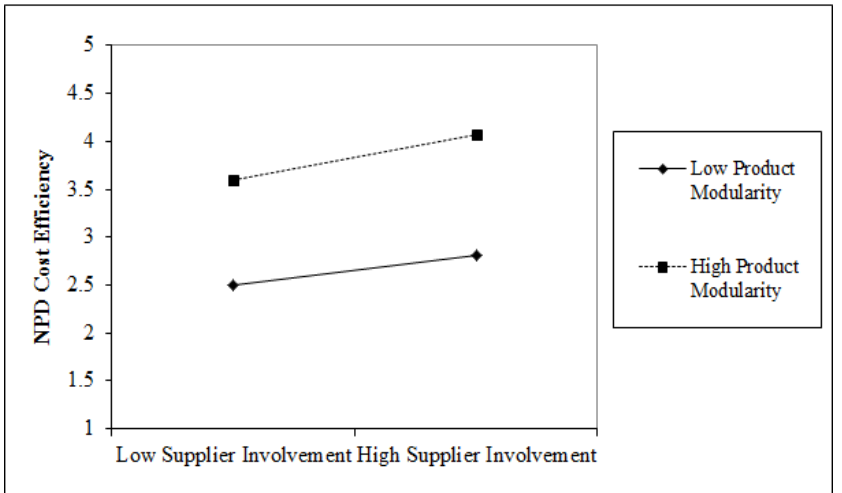

<Figure 2> Interaction Effect of Supplier Involvement and Product Modularity Strategy : NPD cost Efficiency

상호작용이 유의하지 않다면 두 회귀식의 기울기는 평행하 여야 하나, <Figure 2>에서 두 직선의 기울기는 평행하지가 않다. 이것은 곧 상호작용이 유의하다는 것을 의미한다. 더불 어 두 직선의 기울기가 크게 차이가 나지 않는 것은 공급자 참여가 낮은 그룹과 높은 그룹 간 제품 모듈화 전략이 개발비 용 효율성에 미치는 영향이 차이가 있기는 하지만 그렇게 크 지 않다는 것을 의미한다.

다음의 <Figure 3>은 제품 모듈화 전략의 수준에 따라서 공 급자 참여가 신제품 개발성과인 고객만족에 어떠한 변화를 나 타내는지를 표시하였다.

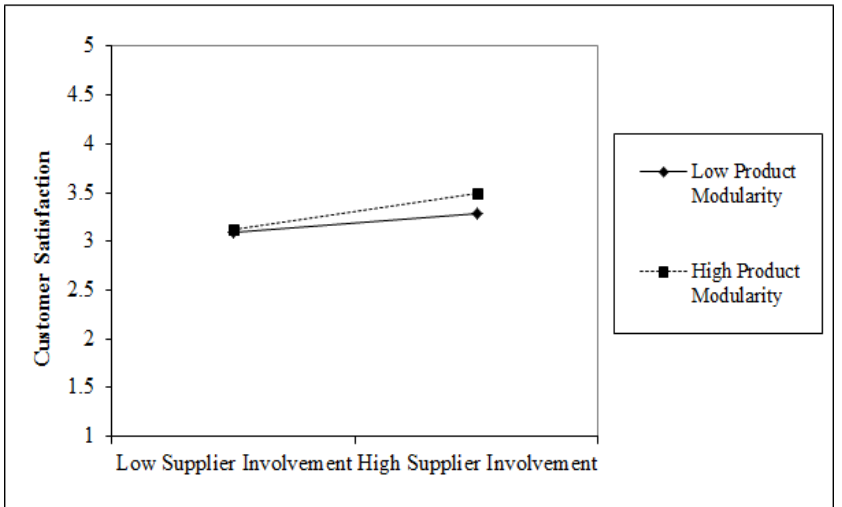

<Figure 3> Interaction Effect of Supplier Involvement and Product Modularity Strategy : Customer Satisfaction

<Figure 2>와 마찬가지로 상호작용이 유의하지 않다면 두 회귀식의 기울기는 평행하여야 하나, <Figure $3>$ 에서도 두 직 선의 기울기는 평행하지가 않다. 이것은 상호작용이 통계적으 로 유의하다는 것을 의미한다. 아울러 공급자 참여가 낮은 그
룹에서는 모듈화 전략이 고객만족에 미치는 영향은 거의 없지 만, 공급자 참여가 높은 그룹에서는 제품 모듈화 전략에 따라 고객만족의 변화가 상대적으로 큰 것을 알 수 있다.

다음으로는 공급자 참여와 대량고객맞춤 전략의 상호작용 효과를 검증하였다. 검증결과, 공급자 참여와 대량고객맞춤 전 략이 신제품 개발 성과에는 상호작용 효과가 없는 것으로 나 타났다. 즉 개발비용 효율성(beta=-.008, p<.1)과 고객만족 (beta=-.009, p<.1) 모두 통계적으로 유의한 효과가 없는 것으 로 확인되었다

\section{6. 토론 및 결론}

\section{1. 연구결과의 토론}

본 연구는 구매자가 신제품을 공동개발하기 위해 공급자를 참여시키는 과정에서 구매자가 추구하는 전략에 따라 공급자 참여의 효과가 신제품개발 성과에 어떻게 달라지는지를 지식 기반이론에 근거하여 실증적으로 검토하였다. 선행연구와 지식 기반이론을 기반으로 공급자의 참여는 신제품개발성과(개발비 용 효율성, 고객만족)에 긍정적인 영향을 미칠 것으로 예상하 였다. 그리고 구매자가 추구하는 전략 중 제품 모듈화 전략은 공급자 참여와 신제품 개발성과(개발비용 효율성, 고객만족)의 관계에서 상호작용효과를 가질 것으로, 대량고객맞춤 전략도 공급자 참여가 신제품 개발성과(개발비용 효율성, 고객만족)에 미치는 영향을 조절할 것으로 가설을 수립하였다.

이러한 가설을 검증하기 위하여 산업통산자원부와 한국생산 성본부가 공동으로 조사한 제조업 생산성 페널 데이터 601 개 를 사용하여 조절회귀분석을 실시하였다. 분석결과 신제품 개 발에서 공급자 참여는개발비용 효율성과 고객만족에 긍정적 영향을 미치는 것으로 나타났다. 이와 같은 결과는 공급자가 가지고 있는 전문지식이 제품의 디자인과 제작을 비롯한 여러 생산과정에 반영되어 신제품개발 성과에 긍정적 영향을 미치 는 최근의 선행연구들과 일치한다고 볼 수 있다(Mackelprang, Robinson, Bernardes, \& Webb, 2014; Ralston, Blackhurst, Cantor, \& Crum, 2014). 이는 빠르게 변화하고 있는 기술변화 속에서 제품개발에 필요한 모든 기술과 지식을 습득하고 소유 하기 보다는 핵심지식을 제외한 나머지 부분에서는 다른 조직 의 전문지식을 차용하는 것이 효과적일 수 있다는 주장과 일 맥상통하는 결과라고 할 수 있다(Grant \& Baden-Fuller, 2004).

이와 같은 공급자 참여와 신제품개발 성과 간 관계에서 구 매자가 적용하는 전략이 어떠한 영향을 미치는지 알아본 결과, 먼저 제품 모듈화 전략은 공급자 참여와 신제품개발 성과인 개발비용 효율성과 고객만족 모두 상호작용의 역할을 하는 것 으로 나타났다. 이러한 결과는 공급자 참여시 구매자가 제품의 모듈화 전략을 사용하는 경우 공급자와 지식을 교환하거나 조 합하거는 과정에서 발생할 수 있는 불확실성을 줄여주기 때문 으로 판단된다(Sanchez \& Mahoney, 1996; Baldwin \& Clark, 2000; Fixson, Khachatryan, \& Lee, 2017). 따라서 신제품개발 과정에서 불확실성을 해결하는 소요비용과 시간을 줄임으로써 개발비용 효율성과 고객만족에 긍정적인 상호작용 역할을 한 것으로 판단할 수 있다.

그리고 두 번째 전략인 대량고객맞춤 전략을 추구하는 경우 에는 공급자 참여와 신제품개발 성과에는 상호작용 효과가 없 
는 것으로 나타났다. 이는 다양한 고객의 욕구를 만족하면서 대량의 물품을 생산해야 하는 대량고객맞춤 전략은 제품의 다 양성으로 인하여 제품과 프로세스의 복잡성(complexity)이 증 가하기 때문에 제품 개발비용의 효율성을 높이기에는 공급자 참여와 동시에 추진하기에는 적절한 전략이 아님을 의미한다 (Blecker \& Friedrich, 2007). 실제로 Holweg and Pil(2004)는 대량고객맞춤 전략이 Make-to-Order 또는 Build-to-Order의 성 격을 가지는 생산방식의 전략으로서 고객의 정확한 정보를 수 집한 이후에야 제작에 들어갈 수 있으며, 다양한 고객의 의견 만큼 복잡성이 증가하여 전체적인 개발 기간이 연장되는 등의 부정적 영향을 미치는 것을 검증하기도 하였다. 이와 같은 대 량고객맞춤 전략의 특징이랄 수 있는 제품의 다양성은 비용과 도 밀접한 관련이 있다. 비록 대량고객맞춤 전략이 대량생산방 식과 비슷한 생산비용이 드는 것을 목표로 하지만, 아직까지는 제품의 다양성과 비용은 상쇄관계(trade-off)이며 제품의 다양 성은 제작자의 입장에서는 복잡성을 증가시키는 주요한 원인 으로 인식된다(Blecker \& Friedrich, 2007). 이와 같은 대량고 객만족에 대한 최근 연구 결과의 연장선상에서 <가설 $3>$ 이 기 각된 것으로 판단된다. 그러나 이러한 결과는 본 연구에서 사 용한 데이터에서 한정하여 이해하는 것이 중요하다. 그리고 연 구결과에 대한 적절한 타당성을 확보하기 위해서는 실증 자료 를 기반으로 한 추후연구가 반드시 필요하다.

\section{2. 학문적 공헌 및 시사점, 향후 연구방향}

본 연구의 학문적 공헌은 다음과 같다. 첫째, 공급자가 참여 하여 신제품을 공동으로 개발하는 경우, 구매자의 전략에 따라 공급자 참여의 효과가 달라지는 것에 대한 실증적 연구가 부 족한 상황에서 본 연구에서 검증한 결과는 학문적 의의가 있 다고 할 수 있다. 이는 Chandler(1962)가 주장한 '구조는 전략 을 따른다(structure follows strategy)'는 명제를 검증하였다는 점에서 주목할 만하다. 그리고 신제품 개발 시 구매자는 어떠 한 전략을 구사하는 것이 구매자 참여의 효과를 높일 수 있는 지에 대하여 실증적 검증을 하였다는 것은 실무적으로도 매우 중요한 시사점을 제시한다고 할 수 있다. 이를 통해 신제품개 발에 대한 학문적 지식을 넓히는데 기여하고 실무적으로도 실 용적인 결과를 제시하였다는 점은 매우 눈여겨 볼 부분이라고 생각한다. 둘째, 본 연구를 수행하기 위해 산업자원부와 한국 생산성본부에서 수집한 제조업 생산성 패널 데이터 601개를 사용하여 검증함으로써 외적 타당성(external validity)을 증대하 였다는 점이다.

본 연구의 한계점은 여러 국가들에서 수집한 자료를 사용하 였으나 각 산업별, 기업 크기별 차이를 직접적으로 통제하지 못하고 더미 변수를 이용하여 통제하였다는 점이다. 추후의 연 구에서는 이러한 점을 보완하여 산업별, 기업크기의 차이를 직 접적, 명시적으로 통제할 수 있는 다층모형분석(multi-level analysis)를 적용한 분석이 필요하다. 둘째, 성과측정변수를 2 차 데이터를 이용하여 객관적인 신제품 개발의 성과를 반영할 필요가 있다. 현실적 한계로 인하여 설문 응답자의 인지적인 측정척도를 사용하였지만, 추후에는 재무재표 등을 이용한 객 관적 자료를 이용한다면 연구의 완전성을 높일 수 있을 것으 로 기대한다.

\section{References}

Aiken, L. S., \& West, S. G. (1991). Multiple Regression: Testing and Interpreting Interactions. Thousand Oaks, CA: Sage.

Baldwin, C., \& Clark, K. (2000). Design Rules: The Power of Modularity. Cambridge, MA: MIT Press

Bayliss, C. Y., \& Clark, K. B. (1997). Managing in an age of modularity. Harvard Business Review, (SeptemberOctober), 84.

Blecker T., \& Friedrich, G. (2007). Guest Editorial: Mass Customization Manufacturing Systems. IEEE Transactions on Engineering Management, 54(1), 4-11.

Camerer, C., George, L., \& Martin, W. (1989). The Curse of Knowledge in Economic Settings: An Experimental Analysis. Journal of Political Economy. 97(5), 12321254.

Carr, A. S., Kaynak, H., \& Hartley, J. L. (2008). Supplier dependence: Impact on supplier's participation and performance. International Journal of Operations and Production Management, 28(9), 899-916.

Chandler, A. D. (1962). Strategy And Structure: Chapters In The History Of The American Enterprise. Cambridge, MA: MIT Press.

Chen I. J., \& Paulraj, A. (2004). Understanding supply chain management: Critical research and a theoretical framework. International Journal of Production Research, 42(1), 131-163.

Chiesa, V., \& Manzini, R. (1998). Organizing for technological collaborations: A managerial perspective. $R \& D$ Management, 28(3), 199-212.

Cho, Y. (2016). The Moderating Effects of Specificity of Technology in the Knowledge Transfer of Distributive Manufacturing MNEs. Journal of Distribution Science, 14(9), 121-132.

Clark, K. B. (1989). Project scope and project performance: The effect of parts strategy and supplier involvement on product development. Management Science, 35(10), 1247-1263.

Clark, K. B., \& Fujimoto, T. (1991). Product Development Performance: Strategy, Organization, and Management in the World Auto Industry. Boston, MA: Harvard University Press,

Cooper, R. G., \& Kleinschmidt, E. J. (1995). Performance Typologies of New Product Projects. Journal of Industrial Marketing Management, 24(2), 439-456.

Davis, S. M. (1989). From "future perfect": Mass customizing. Strategy \& Leadership, 17(2), 16-21.

Dyer, J. H., \& Ouchi, W. G. (1993). Japanese style business partnerships: Giving companies a competitive edge. Sloan Management Review, 35(1), 51-63.

Eisenhardt, K. M., \& Tabrizi, B. N. (1995). Accelerating 
adaptive processes: Product innovation in the global computer industry. Administrative Science Quarterly, 4O(1), 84-110.

Fixson, S. K., Khachatryan, D., \& Lee, W. (2017). Technological Uncertainty and Firm Boundaries: The Moderating Effect of Knowledge Modularity. IEEE Transactions on Engineering Management, 64(1), 16-28.

Fliess, S., \& Becker, U. (2006), Supplier integration: Controlling of co-development processes. Industrial Marketing Management, 35(1), 28-44.

Flynn, B. B., Huo, B., \& Zhao, X. (2010). The impact of supply chain integration on performance: A contingency and configuration approach. Journal of Operations Management, 28(1), 58-71.

Fornell, C., \& Larker, D. F. (1981). Evaluating structural equation models with unobservable measurement error. Journal of Marketing Research, 18(1), 39-50.

Forza, C., \& Salvador, F. (2002). Managing for variety in the order acquisition and fulfillment process: The contribution of product configuration systems. International Journal of Production Economics, 76(1), 87-98.

Galbraith, J. (1973). Designing Complex Organizations. Mass.: Addison-Wesley.

Grant, R. M., \& Baden-Fuller, C. (2004). A knowledge accessing theory of strategic alliances. Journal of Management Studies, 41(1), 61-84.

Gulati, R. (1998). Alliances and networks. Strategic Management Journal, 19(4), 293-317.

Hair, J. F., Black, W. C., Babin, B. J., Anderson, R. E., \& Tatham, R. L. (2010). Multivariate Data Analysis (7th ed.). Upper Saddle River, NJ: Pearson Prentice Hall.

Hart, C. (1995). Mass Customization: Conceptual Underpinnings, Opportunities and Limits. International Journal of Service Industry, 6(2), 36-45.

Hartley, J. L., Zirger, B. J., \& Kamath, R. R. (1997). Managing the buyer-supplier interface for on-time performance in product development. Journal of Operations Management, 15(1), 57-70.

Holcomb, T. R., \& Hitt, M. A. (2007). Toward a model of strategic outsourcing. Journal of Operations Management, 25(2), 464-481.

Holweg M., \& Pil, F. K. (2004). The Second CenturyReconnecting Customer and Value Chain through Build-to-Order. Cambridge, MA: The MIT Press.

Hsuan, J. (1999). Impacts of supplier-buyer relationships on modularization in new product development. European Journal of Purchasing \& Supply Management, 5(3-4), 197-209.

Hwang, S. I., \& Suh, E. G. (2017). A Study on the Effect of Supplier's Strategy on New Product Development
Performance. Journal of Distribution Science, 15(9), 95-107

Kamath, R. R., \& Liker, J. K. (1994). A second look at Japanese product development. Harvard Business Review, 72(6), 154-165.

Kay, M. J. (1993). Making mass customization happen: Lessons for implementation. Planning Review, 21(4), 14-18.

Kennedy, J. (1995). Debiasing the Curse of Knowledge in Audit Judgment. The Accounting Review, 70(2), 249-273.

Kessler, E. H., Bierly, P. E., \& Gopalakrishnan, S. (2000). Internal vs. external learning in new product development: Effects on speed, costs and competitive advantage. R\&D Management, 30(3), 213-224.

Kogut, B., \& Zander, U. (1992). Knowledge of the firm, combinative capabilities, and replication of technology. Organization Science, 3(1), 383-397.

Kotabe, M., Martin, X., \& Domoto, H. (2003). Gaining from vertical partnerships: Knowledge transfer, relationship duration, and supplier performance improvement in the US and Japanese automotive industries. Strategic Management Journal, 24(4), 293-316.

Kotha, S. (1995). Mass customization: Implementing the emerging paradigm for competitive advantage. Strategic Management Journal, 16(S1), 21-42.

Kotha, S. (1996). Mass-customization: A strategy for knowledge creation and organizational learning. International Journal of Technology Management, 11(7-8), 846-858.

Koufteros, X., Vondermbse, M., \& Jayaram, J. (2005). Internal and external integration for product development: The contingency effect of uncertainty, equivocality, and platform strategy. Decision Sciences, 36(1), 97-133.

Koufteros, X. A., Cheng, T. C. E., \& Lai, K. (2007). "Black-box" and "gray-box" supplier integration in product development: Antecedents, consequences and the moderating role of firm size. Journal of Operations Management, 25(4), 847-870.

Leuschner, R., Rogers, D. S., \& Charvet, F. F. (2013). A meta-analysis of supply chain integration and firm performance. Journal of Supply Chain Management, 49(1), 34-57.

Mackelprang, A. W., Robinson, J. L., Bernardes, E., \& Webb, G. S. (2014). The relationship between strategic supply chain integration and performance: A meta-analytic evaluation and implications for supply chain management research. Journal of Business Logistics, 35(1), 71-96.

McGinnis, M. A., \& Vallopra, R. M. (1999). Purchasing and supplier involvement: Issues and insights regarding new product success. Journal of Supply Chain 
Management, 35(2), 4-15.

Petersen, K. J., Handfield, R. B., \& Ragatz, G. L. (2003). A model of Supplier integration into new product development. The Journal of Product Innovation Management, 20(2), 284-299.

Podsakoff, P., MacKenzie, S., Lee, J., \& Podsakoff, N. (2003). Common method biases in behavioral research: $A$ critical review of the literature and recommended remedies. Journal of Applied Psychology, 88(5), 879-903.

Primo, M. A., \& Amundson, S. D. (2002). An exploratory study of the effects of supplier relationships on new product development outcomes. Journal of Operations Management, 20(1), 33-52.

Ragatz, G. L., Handfield, R. B., \& Scannell, T. V. (1997). Success factors for integrating suppliers into new product development. Journal of product innovation management. 14(3), 190-202.

Ralston, P. M., Blackhurst, J., Cantor, D. E., \& Crum, M. R. (2014). A Structure-Conduct-Performance Perspective of How Strategic Supply Chain Integration Affects Firm Performance. Journal of Supply Chain Management, 51(2), 47-64.

Sanchez, R., \& Mahoney, J. T. (1996). Modularity, flexibility, and knowledge management in product and organization design. Strategic Management Journal, 17(Winter Special Issue), 63-76.

Schmidt, J. B. (1995). New Product Myopia. Journal of Business \& Industrial Marketing, Winter Ed., 10(1), 23-34.

Shin, H., Collier, D. A., \& Wilson, D. D. (2000). Supply management orientation and supplier/buyer performance. Journal of Operations Management, 18(3), 317-333.

Song, M., \& Benedetto, C. A. (2008). Supplier's involvement and success of radical new product development in new ventures. Journal of Operations Management, 26(1), 1-22.

Szulanski, G. (1996). Exploring internal stickiness: Impediments to the transfer of best practice within the firm. Strategic Management Journal, 17(special issue), 27-44.

Takeishi, A. (2001). Bridging inter-and intra-firm boundaries: Management of supplier involvement in automobile product development. Strategic Management Journal, 22(5), 403-433.

Tu, Q., Vonderembse, M. A., \& Ragu-Nathan, T. S. (2001). The impact of time-based manufacturing practices on mass customization and value to customer. Journal of Operations Management, 19(2), 201-217.

Tu, Q., Vonderembse, M. A., Ragu-Nathan, T. S., \& Ragu-Nathan, B. (2004). Measuring modularity-based manufacturing practices and their impact on mass customization capability: A customer-driven perspective. Decision Sciences, 35(2),147-168.

Vickery, S. K., Jayaram, J., Droge, C., \& Calantone, R. (2003). The effects of an integrative supply chain strategy on customer service and financial performance: An analysis of direct versus indirect relationships. Journal of Operations Management, 21(3), 523-539.

Yoon, K. (2016). The Effects of Management Consulting Quality and Consultant Capability on Entrepreneurial Firms' Performance. Journal of Distribution Science, 14(5), 81-89. 